\title{
Quantitative evaluation of augmented strain at the weld metal during the Trans-Varestraint test
}

\author{
Shotaro Yamashita ${ }^{1}$ (D) $\cdot$ Shigetaka Okano $^{1} \cdot$ Masahito Mochizuki $^{1} \cdot$ Kazuyoshi Saida $^{1}$
}

Received: 5 March 2021 / Accepted: 8 June 2021 / Published online: 23 June 2021

(C) Crown 2021

\begin{abstract}
The hot cracking susceptibility in the Trans-Varestraint test was evaluated using the nominal strain calculated using the curvature radius of a bending block and the thickness of a specimen based on the theory of material mechanics. The nominal strain was calculated using the material properties at room temperature. Thus, in the Trans-Varestraint test, the non-uniformity of the strain around the weld part due to the temperature distribution is not considered. Therefore, the strain in the Trans-Varestraint test cannot be evaluated correctly. The aim of this study is to reveal the loaded strain at the weld metal to understand the evaluation of hot cracking susceptibility in the Trans-Varestraint test. The loaded strain around the trailing edge of the weld pool of pure iron was measured in-situ using a high-speed camera and high-resolution optical lens. The results of strains measured using image analysis and the finite-element method at the center of the weld bead were compared. Accordingly, it was clarified that the strain was concentrated on the weld part owing to the bending occurring along the weld line, and the strain exceeding the nominal strain was loaded to the trailing edge of the weld pool.
\end{abstract}

Keywords Varestraint test $\cdot$ Strain $\cdot$ Hot cracking susceptibility $\cdot$ Hot ductility curve $\cdot$ In-situ observation

\section{Introduction}

The Varestraint test, proposed by Savage in 1965 [1], has been used for evaluating the susceptibility of weld hot cracking. Since then, many researchers have reported the evaluation result of weld hot cracking susceptibility using the Varestraint test [2-9]. Several approaches in the Varestraint test have been reported for evaluating the type of crack. In this test, a hot crack occurring around the weld pool was evaluated, and the number of cracks, total crack length, and maximum crack length were used as an evaluation index after the test. Various materials, such as stainless steel, nickel-based alloys, aluminum alloys, and carbon steel, have been evaluated by means of their indices. Similarly, hot cracking susceptibility can be approximated using their indices. However, the

Recommended for publication by Commission IX - Behaviour of Metals Subjected to Welding

Shotaro Yamashita

syamashita@mapse.eng.osaka-u.ac.jp

1 Graduate School of Engineering, Osaka University, R2-531, 2-1, Yamada-oka, Suita, Osaka 565-0871, Japan relationship between hot cracking susceptibility and the evaluation indices has not always been explained coherently. Additionally, the relationship between the loaded strain in the Varestraint test and hot cracking susceptibility has not been discussed.

The loaded strain in the Varestraint test is calculated using the curvature radius of a bending block and the thickness of the specimen. Strain is generally defined as $t /(2 R+t)$ or $t / 2 R$ [1]. This expression is derived based on the mechanics of the material as a bending problem at room temperature. Therefore, it is a very convenient index to reflect the crack length and number of cracks easily. However, the use of strain to understand the hot cracking phenomenon might be challenging because strain is calculated as a physical property of the material at room temperature. In practice, bending strain is loaded instantaneously after welding, i.e., bending is performed for the weld metal just below the melting temperature with inhomogeneous temperature distribution. Hence, the loaded strain in the weld metal in the Varestraint test does not obey $t /(2 R+t)$ and $t / 2 R$. Additionally, it might indicate a state of inhomogeneous strain distribution as well as that of the temperature. Therefore, it is necessary to analyze the inhomogeneous state around the weld pool to understand the 
Varestraint test appropriately and reveal the hot cracking phenomenon.

The aim of this study is to experimentally and analytically reveal the loaded strain in the Trans-Varestraint test corresponding to the inhomogeneous temperature distribution. In this study, in-situ observation was used to clarify the strain applied to the weld metal. There are few examples of quantitative measurements using in-situ observations of the strain related to hot cracking. The following is a summary of studies that applied in-situ observations. In 1983, Matsuda reported the result of the strain measurement by means of in-situ observation method for the tensile hot cracking test [10]. Wen and Shinozaki [11] and Kadoi [12] also reported an evaluation result of the strain measurement using an in-situ observation for the U-type hot cracking test. Although many researchers evaluated the hot cracking susceptibilities of various materials, few studies have measured the loaded strain experienced during the Trans-Varestraint test. In 2018, Abe [13] reported a measurement of this strain around the solidification crack using the Trans-Varestraint test. As the measured strain was in good agreement with the convention, there was no clear distinction between the crack occurrence and extension, and the measured minimum strain was the same as that of the conventional strain. However, it was mentioned that excessive strain may have been applied to the weld metal owing to the kink of the specimen $[14,15]$, some questions remain to be answered regarding the arrangement and interpretation of the study. Therefore, an in-situ observation of the TransVarestraint test was performed to explain the relationship between the loaded strain and conventional strain. The loaded strain was estimated using a strain analysis based on the in-situ movie. Moreover, a simulation of the Trans-Varestraint test using the finite-element method (FEM) was conducted to understand the effect of inhomogeneous temperature distribution and to validate the experimental strain. Okano et al. [16-18] proposed that the welding distortion behavior can be predicted accurately by arc physics-based heat source modeling [19, 20]. In this study, the strain at the weld metal was calculated using arc physics-based heat source modeling. The strains, experimentally obtained by the Trans-Varestraint test and analytically estimated using FEM, were compared quantitatively to confirm the correlation and for validation. Then, the correction coefficient to transform $t /(2 R+t)$ to the loaded strain was determined.

\section{Experimental methods}

\subsection{Materials}

The selection of the material is crucial in this study because it is unreasonable to recreate the grain boundary detachment of solid and liquid coexistence regions, such as that in hot cracking. FEM analysis was employed for a continuum model. Therefore, it is desirable to avoid hot cracking on the material surface when measuring the strain via in-situ observation during the Trans-Varestraint test. According to a previous study [7-9, 13] on hot cracking, solidification cracking occurs between the solidification starting temperature and solidification completion temperature. In other words, solidification cracking is less likely to occur in the case of a small solidliquid coexistence temperature range. Therefore, $99.99 \%$ pure iron was used as the test material in this study because it is not susceptible to solidification cracking. The specimen was $5 \mathrm{~mm}$ thick, $50 \mathrm{~mm}$ wide, and $100 \mathrm{~mm}$ long.

\subsection{Trans-Varestraint test}

Figure 1 shows a schematic of the Trans-Varestraint test. The specimen was fixed between the yoke and bending block, as shown in Fig. 1, and welded to the clamp on the bending block to prevent misalignment of the specimen when the yoke was dropped. Gas tungsten arc (GTA) welding was used on the specimen starting from $5 \mathrm{~mm}$ from the edge and stopped when the trailing edge of the weld pool reached the center of the specimen. The bending strain was experienced by the weld metal along the welding direction by the yoke falling just after

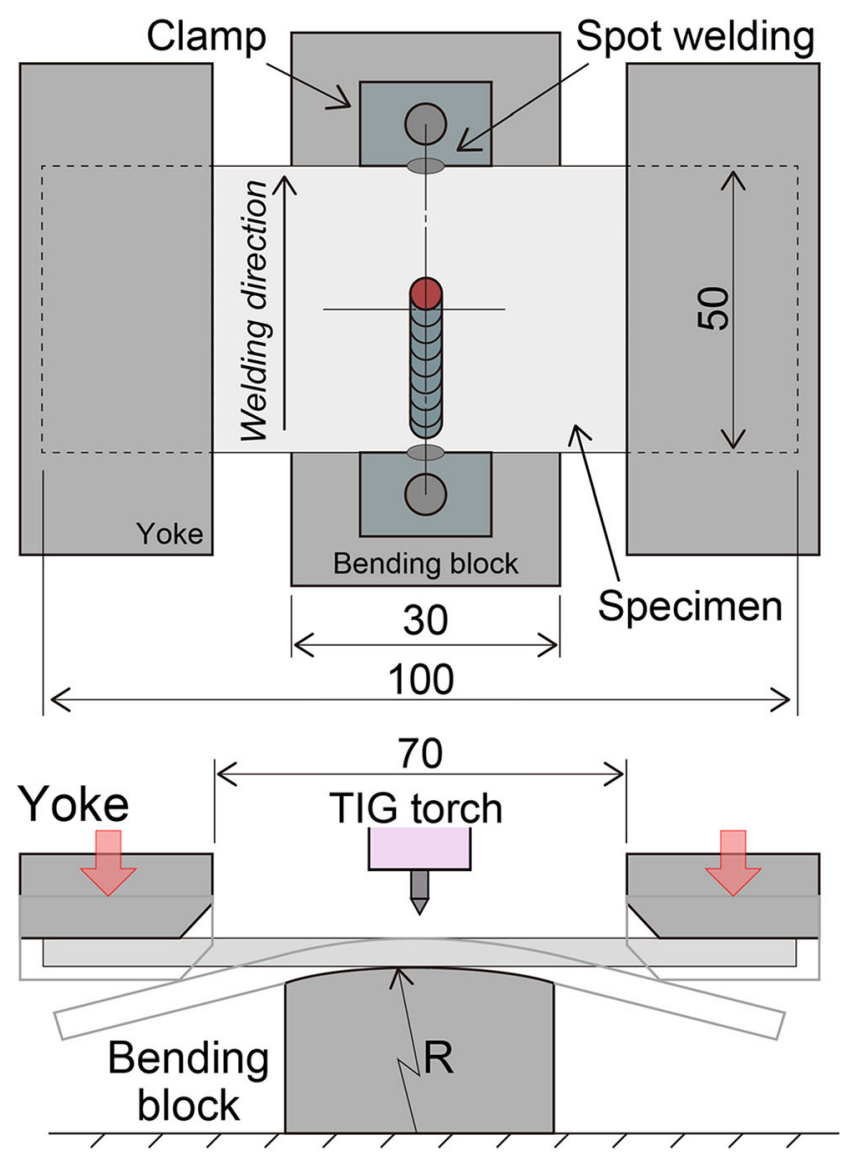

Fig. 1 Schematic of the Trans-Varestraint test 
the extinction of the arc. As reported by Savage et al. [1], the Varestraint test is performed by continuing welding even when the yoke is falling. According to AWS B4.0:2007 and ISO 17641-3:2005(E), it is suggested to continue welding while the yoke is falling. However, if such a method is adopted, the determination of the melting boundary when the yoke is dropped becomes unclear, and the measured crack length is inaccurate after the test [21]. Therefore, in this study, the method of dropping the yoke just after the extinction of the arc was adopted, as described by some researchers [7-9, 13].

The welding conditions are listed in Table 1 . A welding speed of $1.67 \mathrm{~mm} / \mathrm{s}$ and an arc current of 150 A created a halfpenetration bead for the given specimen thickness. The TransVarestraint test conditions are shown in Table 2. The bending speed, which indicates the yoke falling speed, was measured using a high-speed camera. The temperature distribution might change if the falling speed is slow. Therefore, this might change the crack length when the yoke is falling. To avoid this, the falling speed should be as fast as possible. Fortunately, the falling speed of the equipment used in this study was faster than that of the equipment generally used. Additionally, it is not easily affected by a change in temperature distribution when the yoke is dropped. In general, the yoke drop speed was set at 150 to $250 \mathrm{~mm} / \mathrm{s}$ for a welding speed of 1.69 to $2.54 \mathrm{~mm} / \mathrm{s}$ [22], and the yoke falling speed in this study was much faster than that. Because a faster yoke falling speed does not affect the temperature change, it does not significantly affect the test results. However, it is presumed that sufficient care must be taken when handling the crack length caused by temperature changes if the falling speed is slow.

The strain, as shown in Table 2, was calculated using $t /(2 R$ $+t$ ). This strain, based on the mechanics of the material, is referred to as nominal strain. In this study, the TransVarestraint test for pure iron was conducted at nominal strains of $0.8,1.6,2.4$, and $3.4 \%$.

\subsection{In-situ observation}

In-situ observation was used for the Trans-Varestraint test, as shown in Fig. 2. The bending behavior around the weld pool in the Trans-Varestraint test was recorded by a high-speed camera from behind the welding direction. Figure 3 shows

Table 1 Welding conditions

\begin{tabular}{ll}
\hline Wedding speed, $\mathrm{mm} / \mathrm{s}$ & 1.67 \\
Arc current, $\mathrm{A}$ & 150 \\
Arc voltage, $\mathrm{V}$ & 12 \\
Arc length, $\mathrm{mm}$ & 2 \\
Shielding gas $(\mathrm{Ar}), \mathrm{L} / \mathrm{min}$ & 20 \\
Electrode diameter, $\mathrm{mm}$ & 3.2 \\
\hline
\end{tabular}

Table 2 Trans-Varestraint test conditions

\begin{tabular}{lllll}
\hline Bending speed, mm/s & 725 & & & \\
York width, mm & 70 & & & \\
Bending block width, mm & 30 & & & \\
Nominal strain, \% & 3.4 & 2.4 & 1.6 & 0.8 \\
Bending radius, mm & 70 & 100 & 150 & 300 \\
Stroke, mm & 7.0 & 5.4 & 3.8 & 2.0 \\
\hline
\end{tabular}

an image from the in-situ observation movies at a low magnification. The broken line in Fig. 3 indicates the solid-liquid interface between the weld pool and weld metal. The loaded strain was measured in the observation area (Fig. 3), which includes the weld pool and the center of the weld metal, at a high magnification.

The shooting conditions of the in-situ observation process are listed in Table 3. The bending speed was remarkably high, as shown in Table 2. According to the speed and stroke listed in Table 2, the bending time was expected to be between approximately $2.8 \times 10^{-3}$ and $9.7 \times 10^{-3} \mathrm{~s}$. These values are considerably larger than those obtained in other tests. Therefore, the frame rate and exposure were set to be 3500 fps and $3 \mu \mathrm{s}$, respectively, to obtain a clear image. As shown in Fig. 3, the strain perpendicular to the welding direction was measured because the distance along the welding direction was distorted in this observation procedure.

\section{FEM analysis of the Trans-Varestraint test}

A thermal elastic-plastic analysis using FEM was performed to replicate the Trans-Varestraint test using pure iron and to evaluate the loaded strain on the trailing edge of the weld metal quantitatively. According to Okano [19, 20], a more accurate numerical simulation of the weld residual stress and

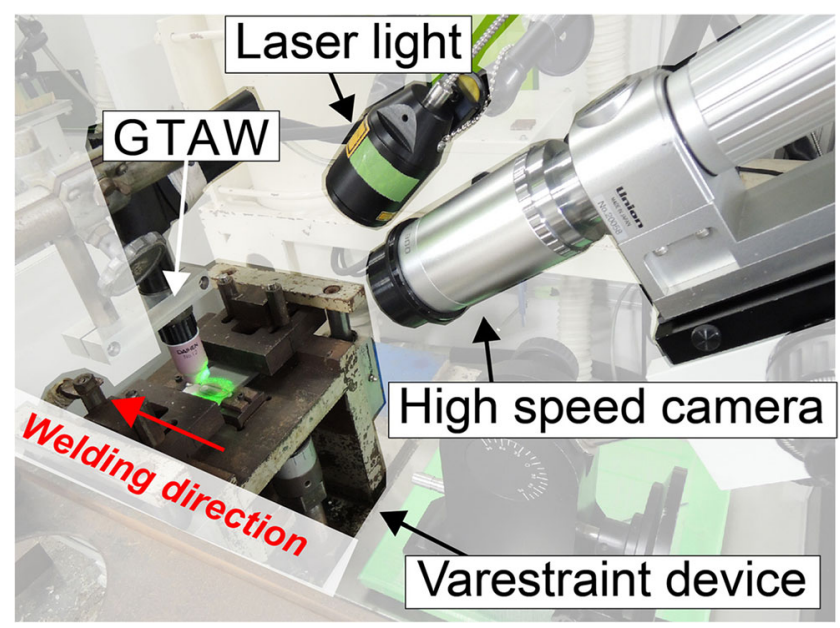

Fig. 2 Experimental setup image of the in-situ observation for the TransVarestraint test 


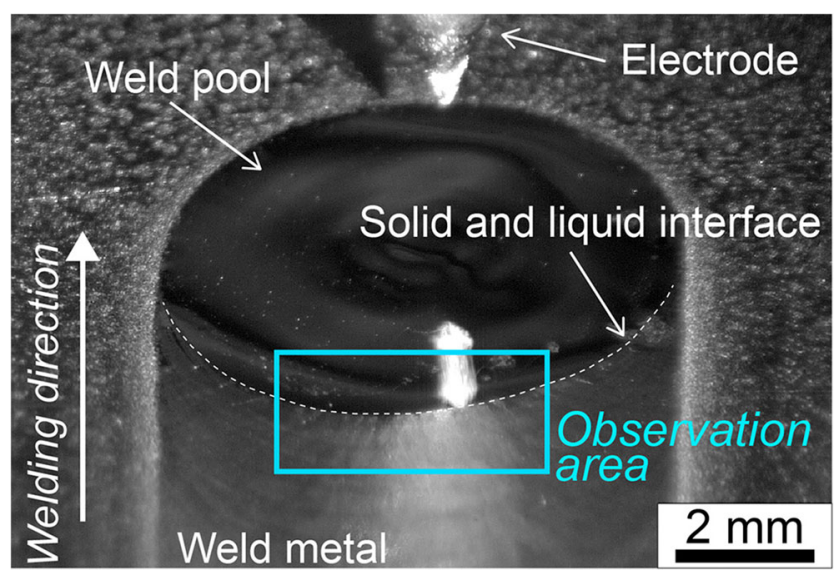

Fig. 3 Image captured by the high-speed camera and laser light

distortion can be achieved by considering the accurate temperature distribution by the heat source modeling based on weld arc physics. Therefore, the simulation, configured as a thermal elastic-plastic analysis with heat source modeling based on weld arc physics, was used to obtain the accurate strain behavior of the weld metal in this study.

Figure 4 shows a schematic model of the Trans-Varestraint test used in this study. The specimen and bending block had the same size and shape as that used in the experiment. In practice, the bending strain on the weld metal was caused by the falling of the yoke. Therefore, the state of bending was simulated by moving the bending block upwards at the state of fixing the yoke and specimen in the simulation. After welding, the shape of the bending radius, bending speed, and bending timing were precisely coordinated with that of the experiment. The bending block was assumed to be a rigid body and the material properties of pure iron were used for the specimen, as shown in Fig. 5.

The bending deformation of the Trans-Varestraint test was simulated using the thermal elastic-plastic analysis. The mechanical properties of pure iron were obtained from the study conducted by Takeda [23]. A material model that considers the temperature dependence was used to simulate the bending deformation accurately. The temperature-dependent properties of Young's modulus, yield stress, Poisson's ratio, and thermal expansion coefficient were considered in the welding thermal elastic-plastic analysis. A plasticity model, which met the von Mises yield criterion and the isotropic hardening rule, was applied to the simulation, and the stress-strain curve was used for the flow stress. The minimum mesh size at the center of the specimen was set to $0.5 \mathrm{~mm}$ for consistency with the

Table 3 Shooting conditions

\begin{tabular}{ll}
\hline Frame rate & 3500 \\
Exposure, $\mu \mathrm{s}$ & 3 \\
Resolution, pixel & $1024 \times 768$ \\
Magnification, $\mu \mathrm{m} /$ pixel & $3 \sim 5$ \\
\hline
\end{tabular}

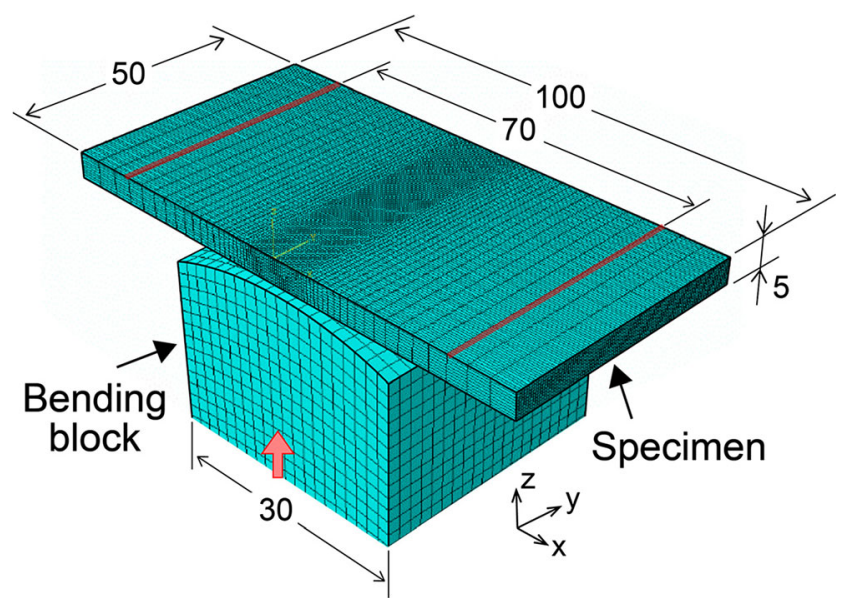

Fig. 4 Trans-Varestraint test model used in the FEM analysis

experimental measurement procedure. The gage length for the loaded strain measurement in the experiment is described below. The $z$-axis representing the thickness of the specimen was segmented at intervals of $0.25 \mathrm{~mm}$. The initial temperature of the model was $20^{\circ} \mathrm{C}$, whereas the thermal radiation was 0.4 in accordance with the Stefan-Boltzmann law of radiation. The heat transfer to air was considered as the boundary condition in this analysis. Further details on the simulation have been reported in references [17-19].

\section{Experimental results}

\subsection{Influence of gage length on image analysis}

It is considered that the strain changes in accordance with the gauge length because the strain was measured at the inhomogeneous temperature distribution and mixing solid and liquid. In this section, the influence of gage length is discussed. The

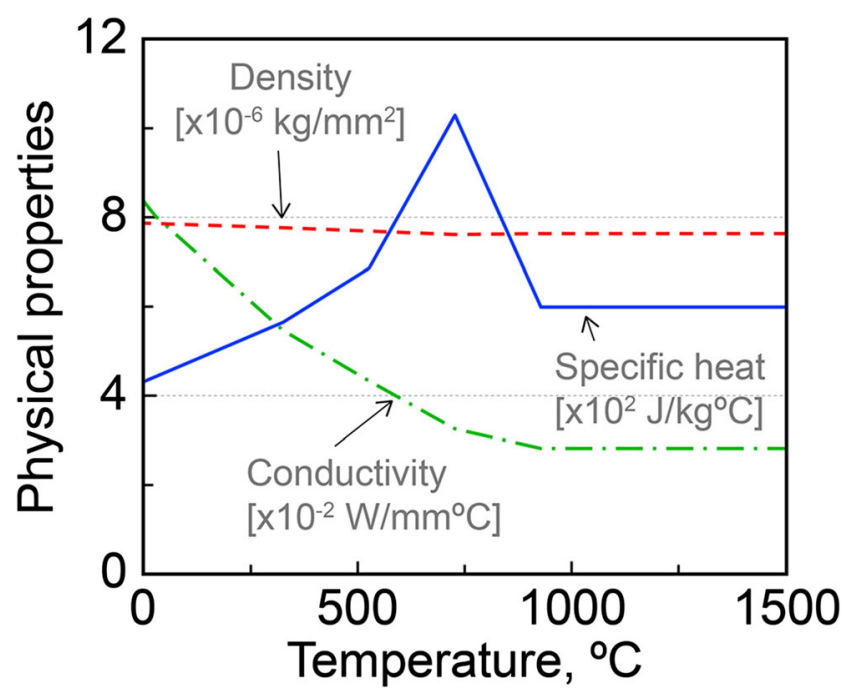

Fig. 5 Material constants as functions of temperature 
result of the in-situ observation around the weld pool at the nominal strain of $3.4 \%$ is shown in Fig. 6. The images recorded just before the bending to bending completion are shown in Fig. 6. The broken line indicates the solid-liquid interface, whereas the crisscross marks on the trailing edge of the weld pool are reference points for strain measurement. Figure 6 shows that the visage on the weld metal and shape of the solid-liquid interface changed considerably. After the TransVarestraint test, the same area, as in the in-situ observation, was observed to confirm hot cracking. However, hot cracking did not occur there because the temperature range between $T_{\mathrm{L}}$ and $T_{\mathrm{S}}$ did not exist theoretically. Thus, the strain at the weld metal of pure iron obtained experimentally was assumed to be the strain experienced by the continuous body. In addition, the state of the specimen after the Trans-Varestraint test was not bent along the curvature radius of the bending block, and the kink of the specimen was observed.

The influence of gage length, which was evaluated by changing the gage length from 0.2 to $3.0 \mathrm{~mm}$ at a nominal strain of $3.4 \%$, is shown in Fig. 7. The measured strain increased with the decrease in gage length. Additionally, the minimum strain, which was obtained at a value over $1.0 \mathrm{~mm}$, exceeded the nominal strain of $3.4 \%$ by at least five times that of the nominal strain. In the Trans-Varestraint test, hot cracking occurs at the grain boundary between the two grains. Therefore, the gage length should be smaller than or equal to the two-grain width to explain the local strain corresponding to the hot cracking behavior. The grain width was approximately 0.3 to $0.5 \mathrm{~mm}$ considering type $310 \mathrm{~S}$ stainless steel as an example. A resolution problem existed in the in-situ observation. However, it is unreasonable to simulate the tailored FEM analysis for a mesh size similar to the gage length. Thus, the gage length in this study was determined to be 0.5 $\mathrm{mm}$, and the image analysis was performed with this gage length, as described in the following section.

\subsection{Measured strain on the weld metal}

Figure 8 shows the variation in the measured strain with time at the center of the weld bead at each nominal strain. The

Fig. 6 In-situ observation around the weld pool during bending at a nominal strain of $3.4 \%$

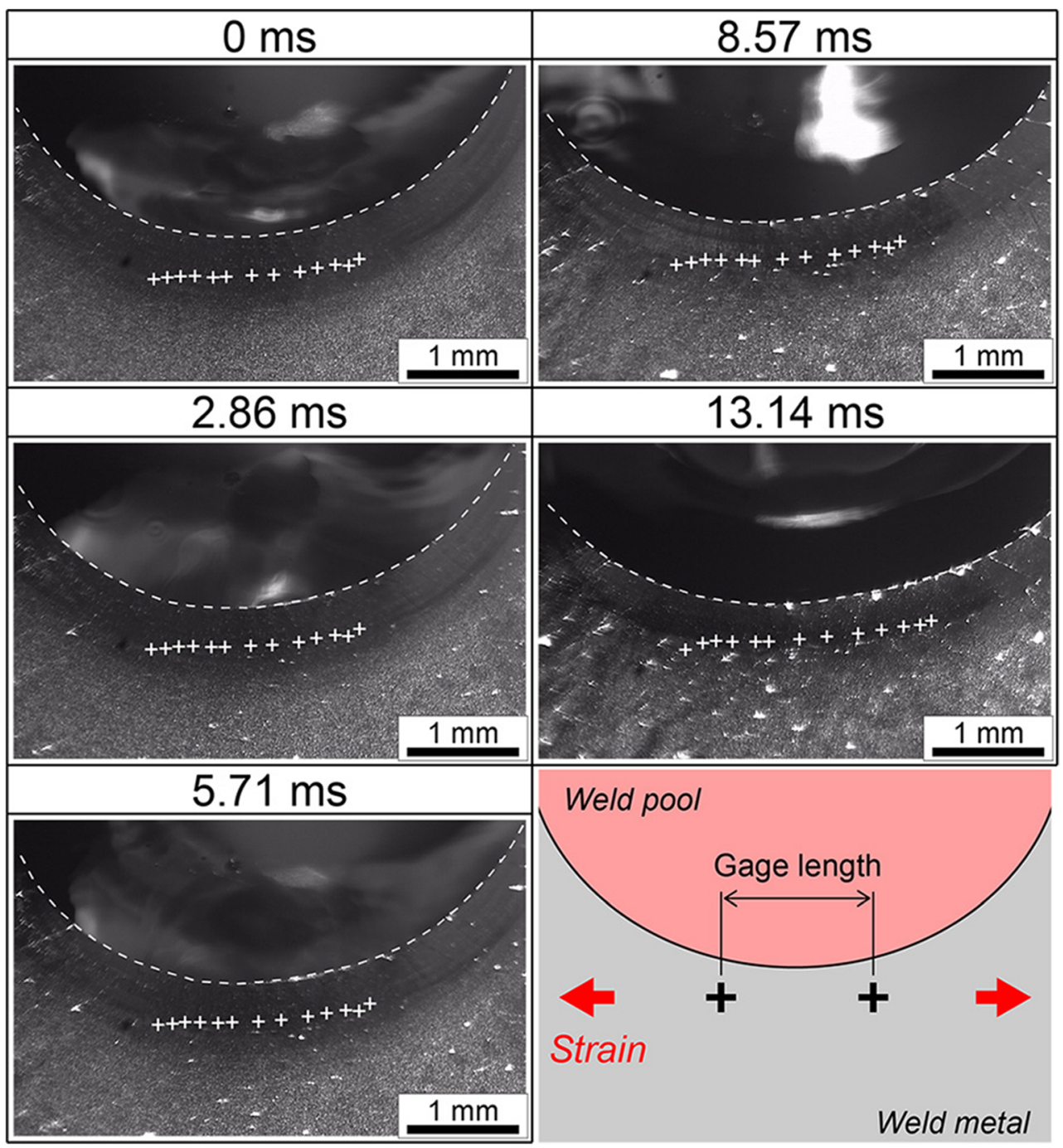




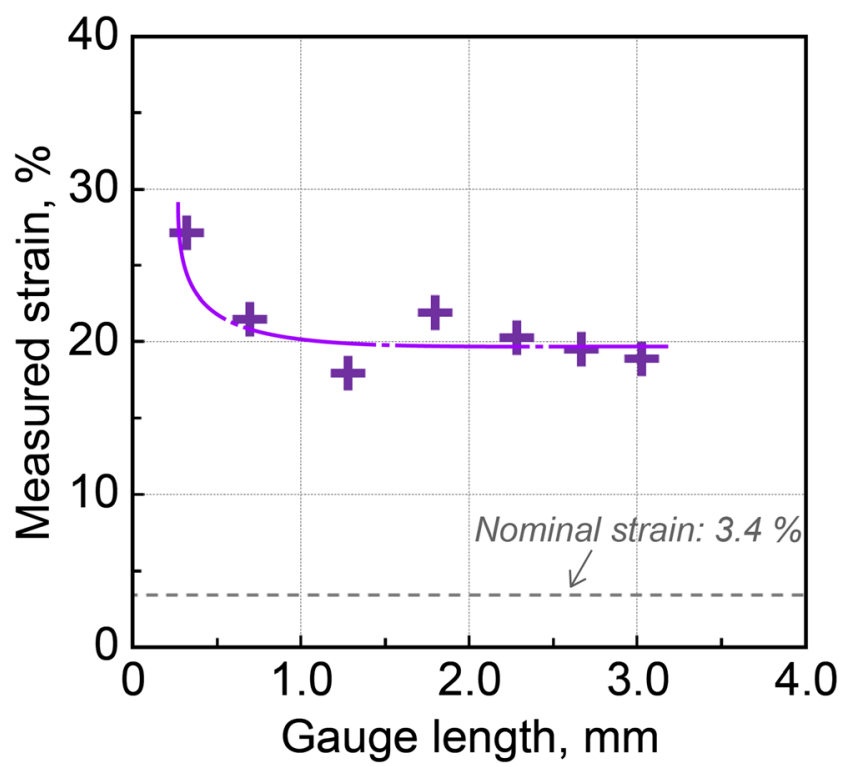

Fig. 7 Relationship between the gage length and measured strain at the center of the weld bead

bending time increased with the increase in nominal strain because the strain controlled the stroke of the yoke at the same bending speed, as listed in the Table 2. The measured strain at the completion of the bending increased with the nominal strain. Notably, the measured strain at the nominal strain of $0.8 \%$ exceeded the nominal strain of $3.4 \%$. Additionally, the bending behavior in the Trans-Varestraint test was extremely rapid compared to the solidification cracking in the U-type hot cracking test [24], as the maximum bending time at a nominal strain of $3.4 \%$ was only $0.012 \mathrm{~s}$.

The relationship between the measured strain and nominal strain is presented in Fig. 9, which shows that the measured strain was considerably higher than the nominal strain. The measured strain exhibits good linearity with respect to the

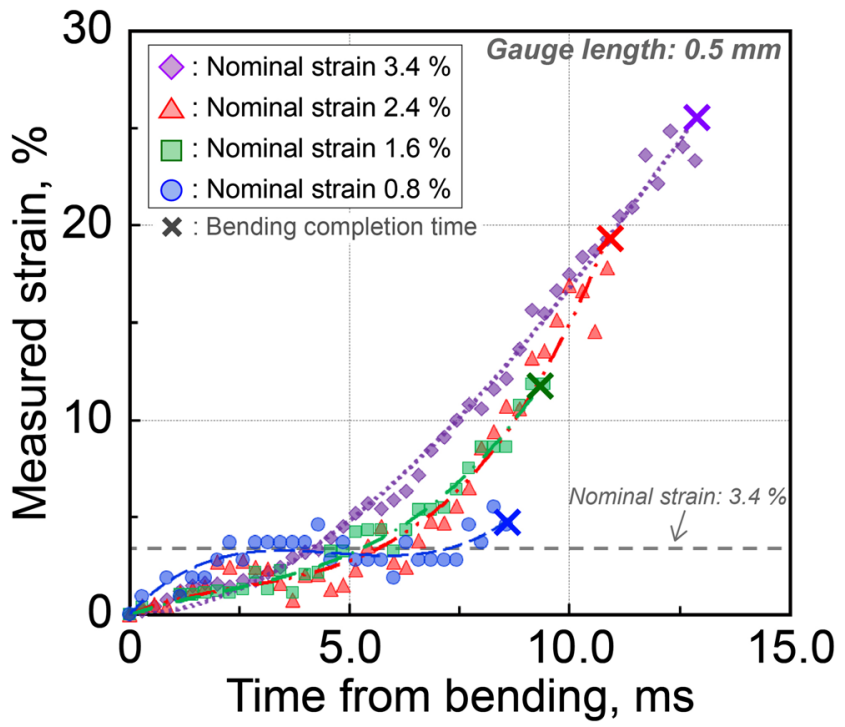

Fig. 8 Time history of measured strain on the weld metal (pure iron)

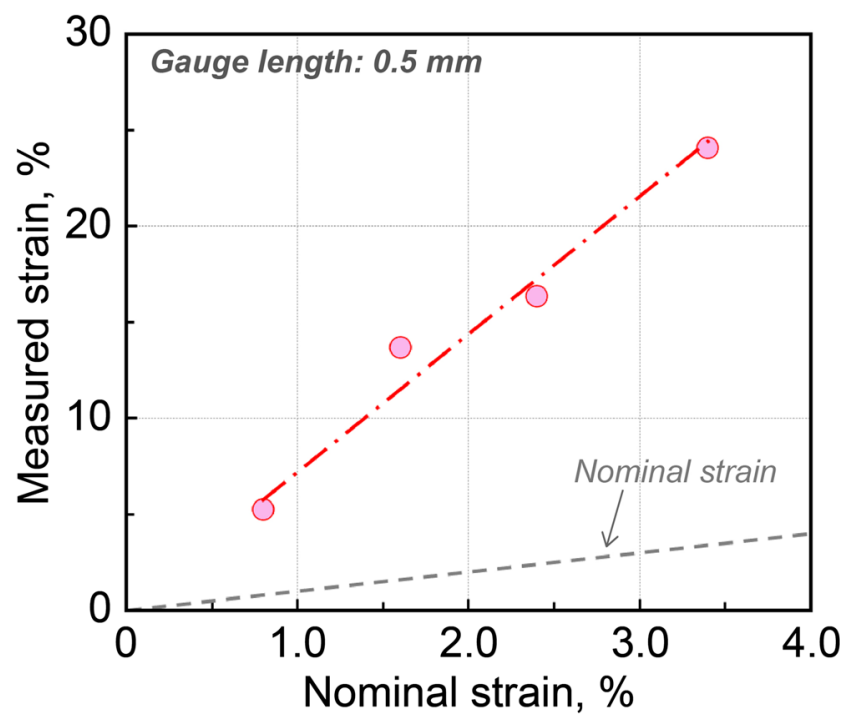

Fig. 9 Relationship between measured stain and nominal strain of pure iron

nominal strain. Therefore, it is expressed by Eq. (1).

$\varepsilon_{\text {measured }}=7.2 \cdot \varepsilon_{\text {nominal }}$

It can be presumed that the loaded strain on the weld metal, which is approximately seven times the nominal strain, is loaded at a gage length of $0.5 \mathrm{~mm}$. The main cause of the increase in strain can be attributed to temperature distribution during and after welding in the Varestraint test. Thus, the FEM analysis based on accurate temperature distribution was performed to confirm the effect of temperature on strain around the weld pool, as described in the next section.

\section{Simulated strain in the Trans-Varestraint test}

The temperature and strain distributions calculated by the thermal elastic-plastic analysis with heat source modeling based on weld arc physics are shown in Fig. 10. The temperature distribution under GTA welding conditions before bending is shown in the top left panel of Fig. 10, whereas the bottom left panel shows the strain distribution at that time. According to the state of strain distribution before bending, the compressive strain seemed to be loaded around the weld pool because it was constrained from the surroundings by thermal expansion. The strain distribution changes in accordance with the nominal strain. Thus, the analysis results indicated that the bending of the specimen occurred around the weld line and did not follow the curvature of the bending block. This type of kink was also observed in the experimental results. As shown in Fig. 1, the specimen was subjected to bending with a yoke and bending block, fixing the entire width of the specimen. If the 


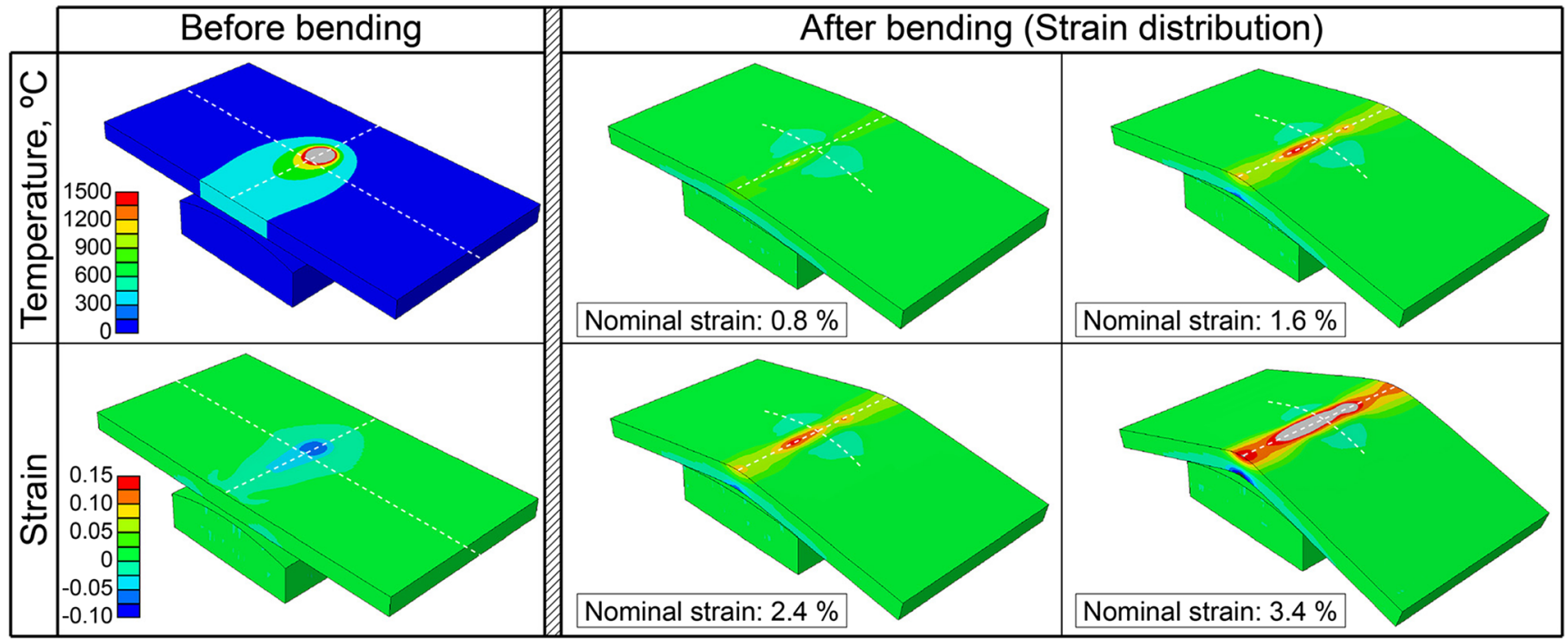

Fig. 10 Temperature distribution before bending and the corresponding strain distribution

temperature distribution owing to welding existed even partially, the stiffness of the entire specimen width would be lower than that of other regions. Bending occurred mainly in the low stiffness region. Therefore, the strain on the weld line increased entirely with the nominal strain. In particular, the strain distribution around the weld pool and trailing edge of the weld, such as the region with a relatively high temperature, changed remarkably. Thus, the change in strain might depend on the existing high-temperature part with characteristics, such as low stiffness.

The calculated strain at the center of weld metal near the weld pool at different nominal strain in the simulation is shown in Fig. 11. It can be observed that the calculated strain increased with the increase in nominal strain. The calculated strain was compared to the measured strain in Fig. 12. The calculated strain is in good agreement with the measured

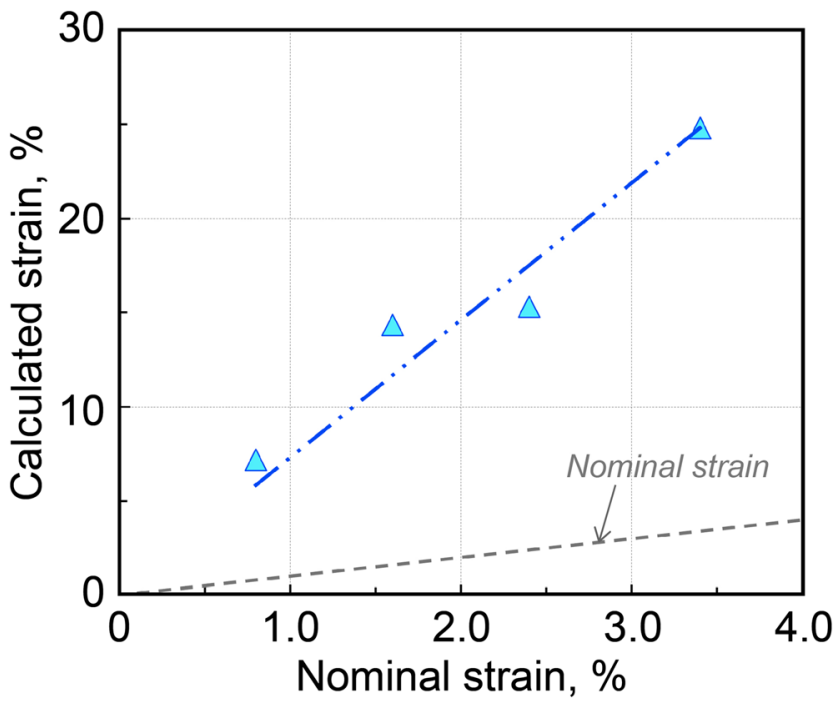

Fig. 11 Relationship between the calculated stain and nominal strain of pure iron strain. In other words, the simulation results indicated that the strain on the weld metal became seven times the nominal strain. For verification, the strain at a room temperature of 20 ${ }^{\circ} \mathrm{C}$ was calculated (Fig. 13). The strain at the center of the weld bead was $3.4 \%$ without welding when the nominal strain was $3.4 \%$, and the specimen without the temperature distribution bends in the shape of the bending block radius. According to these results, the amplification of the strain on the weld metal shows that it depends on the temperature distribution imposed by the welding. Moreover, this proves that the loaded strain at a gage length of $0.5 \mathrm{~mm}$ is approximately seven times the nominal strain. These data also indicated that the kink in the specimen was caused by the bending around the weld line, which became less rigid owing to the presence of a nonuniform temperature distribution; therefore, the strain exceeding the nominal strain was applied to the weld metal.

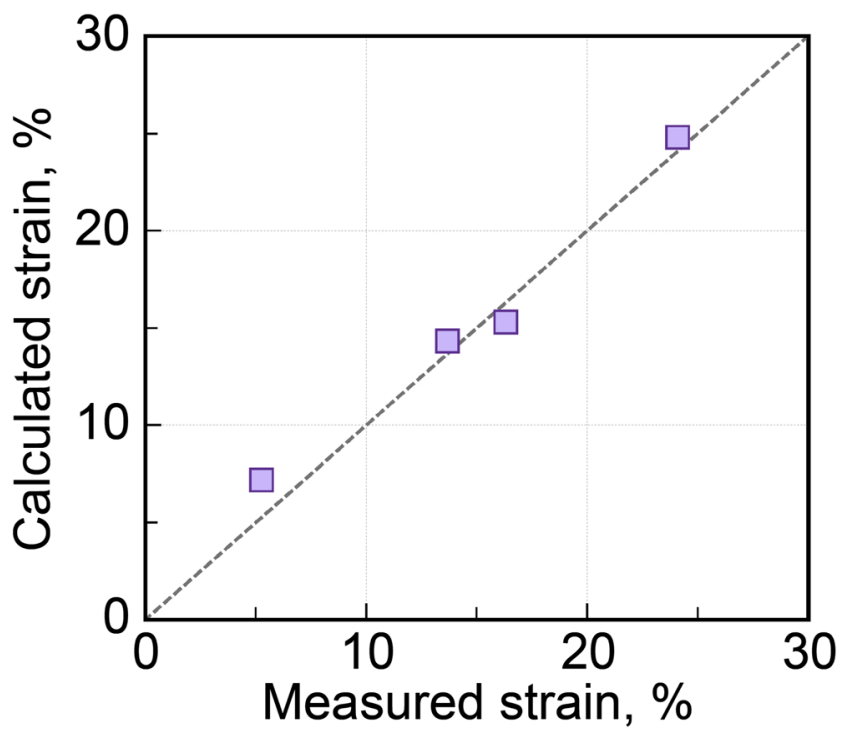

Fig. 12 Correlation between the measured and calculated strains 


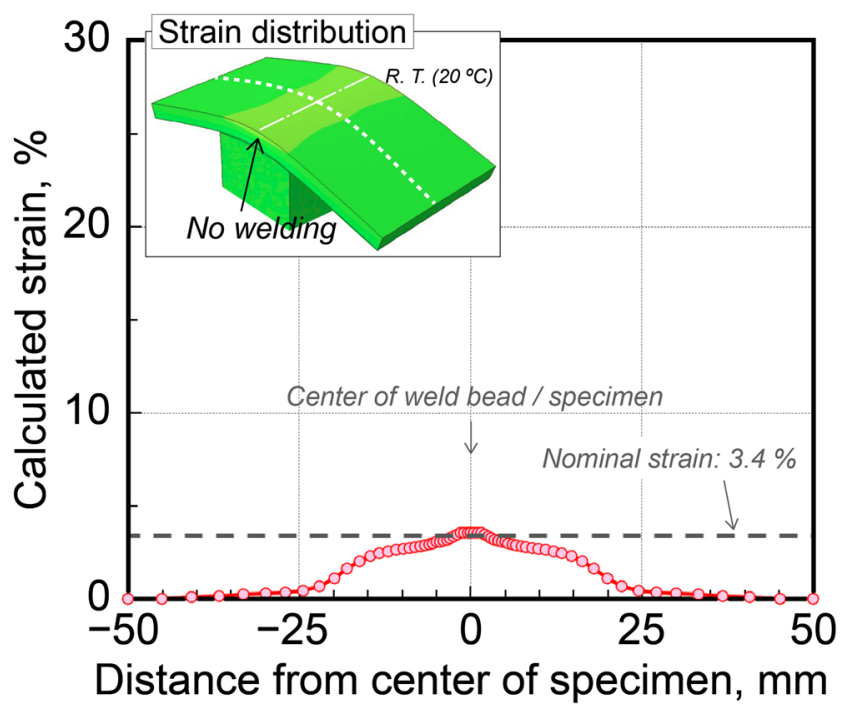

Fig. 13 Strain distribution at room temperature

\section{Consideration for the loaded strain in the Trans-Varestraint test}

The Trans-Varestraint test can be used to evaluate the hot cracking susceptibility using the maximum crack length at each nominal strain. Subsequently, the temperature range, such as BTR (Solidification brittle temperature range), in the case of solidification crack was obtained by converting the crack length by using the temperature profile. BTR is determined by the saturation value of the crack length obtained by the primary arrangement of the crack length using the nominal strain. Based on the results obtained in this study that the measured strain increased with an increase in nominal strain, the use of nominal strain for the primary arrangement was considered to be effective. On the other hand, the curve obtained in the process of confirming the BTR is defined as the hot ductility curve of solidification cracking with temperature on the horizontal axis and ductility on the vertical axis. Hot cracking occurs when the ductility curve and thermal strain of the weld bead intersect [25]. It is important that the curve defines the criterion of solidification cracking occurrence, i.e., the clarification of ductility on the vertical axis expressed by the strain in the Trans-Varestraint test is important to explain the characteristics of solidification cracking susceptibility.

In this regard, the in-situ observation and simulation show that the cracking in the Trans-Varestraint test might have occurred under a considerably higher strain than the nominal strain, which is expressed by the specimen thickness and bending radius. In other words, the existing ductility curve $[26,27]$ will rise according to Eq. (1). Equation (1) was derived at a gage length of $0.5 \mathrm{~mm}$. Its amplification at a gage length of $3.0 \mathrm{~mm}$ is at least 5 times, as shown in Fig. 7. This results in the increase in the augmented strain of the ductility curve. In particular, $\varepsilon_{\min }$, one of the evaluation indices of the Trans-Varestraint test, increases in accordance with Eq. (1). The cause for the increase in strain is the temperature distribution during welding. When a high-temperature softened region exists at the center of the bending region in the TransVarestraint test, the bending does not follow the bending block radius and instead concentrates on the weld metal in the bending center consequently. This was inferred to be responsible for producing the kink of the specimen. However, these results were obtained based on the continuous body (e.g., pure material and FEM analysis). In other words, the nominal strain obtained using $t / 2 R$ or $t /(2 R+t)$ is effective for the primary arrangement as the global strain applied to the entire specimen. Meanwhile, the bending in the actual Varestraint test with welding occurs along the weld part. This results in strain concentration. Thus, the use of nominal strain is not suitable for the essential discussion of hot ductility.

Notably, the strains evaluated in this study were the results obtained with pure iron, and the initiation strain of crack occurrence was not evaluated. The application of this result should be carefully considered when evaluating practical materials, such as carbon steel, stainless steel, Ni-based alloys, and aluminum alloys. Further analyzes of practical materials should be conducted to better understand the hot cracking phenomenon and Varestraint test, particularly to obtain the critical strain of solidification cracking in the Varestraint test.

\section{Conclusions}

In-situ observations were conducted for the Trans-Varestraint test to obtain the loaded strain on the weld metal. Additionally, FEM analysis was performed based on the thermal elasticplastic model with heat source modeling based on weld arc physics. The results obtained by these analyzes are summarized below.

(1) The strain measured at gage lengths of approximately $0.2-3.0 \mathrm{~mm}$ exceeded the nominal strain.

(2) At a gage length of $0.5 \mathrm{~mm}$, the measured strain was estimated to be seven times the nominal strain.

(3) The FEM analysis considering the accurate temperature distribution indicated the same increment rate as that of the measured strain.

(4) According to the experimental and simulation results, the loaded strain in the Trans-Varestraint test was seven times the nominal strain at the gage length of $0.5 \mathrm{~mm}$. Even if the gage length was $3.0 \mathrm{~mm}$, the strain was at least five times larger. 
Funding This research was supported by the Japan Society for the Promotion of Science KAKENHI under Grant Numbers JP18K13938 and JP20K05154.

Open Access This article is licensed under a Creative Commons Attribution 4.0 International License, which permits use, sharing, adaptation, distribution and reproduction in any medium or format, as long as you give appropriate credit to the original author(s) and the source, provide a link to the Creative Commons licence, and indicate if changes were made. The images or other third party material in this article are included in the article's Creative Commons licence, unless indicated otherwise in a credit line to the material. If material is not included in the article's Creative Commons licence and your intended use is not permitted by statutory regulation or exceeds the permitted use, you will need to obtain permission directly from the copyright holder. To view a copy of this licence, visit http://creativecommons.org/licenses/by/4.0/.

\section{References}

1. Savage WF, Lundin CD (1965) The Varestraint test. Weld J 44: $433 \mathrm{~s}-442 \mathrm{~s}$

2. Lingenfelter AC (1972) Varestraint testing of nickel alloys. Weld J $51: 430 \mathrm{~s}-436 \mathrm{~s}$

3. Arata Y, Matsuda F, Saruwatari S (1974) Varestraint test for solidification crack susceptibility in weld metal of austenitic stainless steels. Trans JWRI 3:79-88

4. Lippold JC, Savage WF (1982) Solidification of austenitic stainless steel weldments: part III-the effect of solidification behavior on hot cracking susceptibility. Weld J 61:388s-396s

5. Lippold JC, Baeslack WA III, Varol I (1992) Heat-affected zone liquation cracking in austenitic and duplex stainless steels. Weld $\mathrm{J}$ $71: 1 \mathrm{~s}-14 \mathrm{~s}$

6. Ernst SC, Baeslack WA III, Lippold JC (1989) Weldability of highstrength low-expansion superalloys. Weld J 68:418s-430s

7. Saida K, Okabe Y, Hata K, Nishimoto K, Kiuchi K, Nakayama J (2010) Hot Cracking Behaviour and Susceptibility of Extra High Purity Type 310 Stainless Steels. Sci Technol Weld Join 15:87-96

8. Chun EJ, Baba H, Nishimoto K, Saida K (2015) Development of laser beam welding transverse-varestraint test for assessment of solidification cracking susceptibility in laser welds. Met Mater Int 21:543-553

9. Wang D, Kadoi K, Shinozaki K, Yamamoto M (2016) Evaluation of solidification cracking susceptibility for austenitic stainless steel during laser Trans-Varestraint test using two-dimensional temperature measurement. ISIJ Int 56:2022-2028

10. Matsuda F, Nakagawa H, Nakata K, Kohmoto H, Honda Y (1983) Quantitative evaluation of solidification brittleness of weld metal during solidification by means of in-situ observation and measurement (report I). Trans JWRI 12:65-72

11. Wen P, Shinozaki K, Yamamoto M, Senda Y, Tamura T, Nemoto N (27, 2009) In-situ Observation of Solidification Cracking of Laser Dissimilar Welded Joints, Quar. J JWS:134s-138s

12. Kadoi K, Fujinaga A, Yamamoto M, Shinozaki K (2013) The Effect of welding conditions on solidification cracking susceptibility of type $310 \mathrm{~S}$ stainless steel during laser welding using an in-situ observation technique. Weld World 57:383-390

13. Abe D, Matsuzaka F, Murakami Y, Matsuoka T, Yamaoka H (2018) Determining the BTR by conducting a Trans-Varestraint Test using a high-speed camera and two-color pyrometry. Weld World 62:1237-1246

14. Shankar V, Gill TPS, Mannan SL, Sundaresan (2000)2) Criteria for hot cracking evaluation in austenitic stainless steel welds using longitudinal varestraint and transvarestraint tests. Sci Technol Weld Join 5:91-97

15. Andersson J, Jacobsson J, Brederholm A (2016) Improved Understanding of Varestraint Testing - Nickel-Based Superalloys. In: Boellinghaus T, Cross CE, Lippold JC (eds) Cracking Phenomena in Welds IV. Springer, Berlin, pp 25-36

16. Okano S, Kobayashi S, Kimura K, Ando A, Yamada E, Go T, Murakami H, Mochizuki M (2016) Experimental and numerical investigation on generation characteristics of welding deformation in compressor impeller. Mater Des 101:160-169

17. Okano S, Mochizuki M (2017) Transient distribution behavior during TIG welding of thin steel plate. J Mater Process Technol 241: 103-111

18. Okano S, Tsuji H, Mochizuki M (2017) Temperature distribution effect on relation between welding heat input and angular distortion. Sci Technol Weld Join 22:59-65

19. Okano S, Tanaka M, Mochizuki M (2011) Arc physics based heat source modeling for numerical simulation of weld residual stress and distortion. Sci Technol Weld Join 16:209-214

20. Okano S, Mochizuki M, Yamamoto K, Tanaka M (2011) An attempt to enhance numerical models of angular distortion by considering the physics of the welding arc. Weld World 55:93-100

21. Kadoi K, Okano S, Yamashita S, Abe D, Takemori A, Yamada S, Takada A, Kawata J (2019) Investigation of standardizing for evaluation method of transverse-varestraint test. Weld Int 33:189-199

22. Lippold JC, Kotecki DJ (2005) Welding metallurgy and weldability of stainless steels. A John Wiley \& Sons, inc., Croydon, UK, pp 312-316

23. Takeda Y, Kiattisaksri C, Aramaki M, Munetoh S, Furukimi O (2016) Effects of tensile test specimen thickness on elongation and deformation energy for industrial pure iron. Tetsu to Hagane 102:599-606

24. Shinozaki K, Kuroki H, Luo X, Ariyoshi H, Shirai M (1999) Comparison of hot cracking susceptibilities of various Ni-base, heat-resistant superalloys by U-type hot cracking test. Study of laser weldability of Ni base, heat resistant superalloys ( $2^{\text {nd }}$ Report). Weld Int 13:952-959

25. Prokhorov NN (1962) The Technological Strength of Metals while Crystallising during Welding, Star. Proiz 4:1-5

26. Senda T, Matsuda F, Takano G (1973) Studies on solidification crack susceptibility for weld metals with Trans-Varestraint test. J Jpn Weld Soc 42:48-56

27. Nakata K, Matsuda F (1995) Evaluations of ductility characteristics and cracking susceptibility of Al alloys during welding. Trans JWRI 24:83-94

Publisher's note Springer Nature remains neutral with regard to jurisdictional claims in published maps and institutional affiliations. 